\title{
O conceito de ecossistema, a ideia de equilíbrio e o movimento ambientalista*
}

\author{
The concept of ecosystem, the idea of balance and the \\ environmental movement
}

\author{
José Eduardo Viglio*1 \\ Lúcia da Costa Ferreira*2
}

\section{Palavras- chaves: \\ Sociologia ambiental; Ambientalismo; Teoria ecológica.}

Resumo: A ecologia enquanto disciplina científica foi encarada pelos movimentos ambientalistas a partir de 1960 como uma grande aliada da causa ambiental. Um conjunto de conceitos e ideias permitiu ao ambientalismo construir suas percepções a respeito dos problemas ambientais e de suas resoluções e, ao mesmo tempo, por possuir status científico, a ecologia contribuiu para que 0 ambientalismo adquirisse considerável força política. Contudo, tal conjunto de conhecimentos oferecido pela ecologia constitui uma abordagem particular da mesma e que desde a década de 1970 vem sendo questionada e apontada por muitos ecólogos como pertencente ao antigo paradigma ecológico. Independentemente de uma mudança paradigmática, as novas ideias no âmbito da ecologia permitiram aos ecólogos uma "releitura" dos fenômenos ecológicos a ideia de equilíbrio como propriedade intrínseca dos sistemas ecológicos foi amplamente revista. Nesse sentido, esse ensaio pretende apresentar de forma sintética as principais controvérsias no campo da ecologia em relação ao conceito de ecossistema e da ideia de equilíbrio para em seguida discutir o papel desempenhado por essas noções nos discursos dos movimentos ambientalistas contemporâneos.

\footnotetext{
* Artigo recebido em 14/01/2013 e aceito para publicação em 09/06/2013.

*1 Pesquisador de pós-doutorado do Núcleo de Estudos e Pesquisas Ambientais da Unicamp. Contato: eduviqlio@hotmail.com.

*2 Ecóloga e doutora em ciências sociais pela Unicamp. Pesquisadora do Núcleo de Pesquisas Ambientais NEPAM/UNICAMP.
} 
Keywords: Abstract: Ecology as a scientific discipline was regarded by

Environmental

Sociology;

Environmentalism;

Ecological theory. environmental movements since 1960 as a great allied of the environmental cause. A series of concepts and ideas allowed environmentalism to build their perceptions of environmental problems and their resolutions and at the same time by having scientific status, ecology contributed to environmentalism acquired considerable political power. However this stock of knowledge offered by the ecology constitutes a particular approach of ecological science that the 70 has been questioned by many ecologists that pointed this approach as belonging to the old ecological paradigm. Regardless of a paradigm shift, the new ideas within the ecology allowed the environmentalists a "reinterpretation" of ecological phenomena-the idea of balance as intrinsic property of ecological systems has been extensively revised. In this sense, this essay intends to present in a synthetic way the major controversies in the field of ecology in relation to the ecosystem concept and the idea of balance to then discuss the role of these notions in the discourse of contemporary environmental movements.

\section{Introdução}

ecologia originalmente definida em 1866 por Ernest Haeckel como a A "ciência capaz de compreender as relações do organismo com seu - ambiente" ou, mais recentemente, como o "estudo científico da distribuição e abundância de organismos e das interações que determinam a distribuição e abundância" (TOWNSEND et al., 2006, p. 24) é vista como um dos principais pilares teóricos do ambientalismo contemporâneo (MCINTOSHI, 1985; MOORE, 1987; NICHOLSON, 1989; YEARLEY, 1989; RUBIN, 1994; HANNIGAN, 1995; SCOONES, 1999).

A maneira como o mundo natural é valorizado, classificado, categorizado e interpretado emerge de uma tradição particular da ecologia (KWA, 1987; SCOONES, 1999). A abordagem ecossistêmica ${ }^{1}$ da ecologia e seu entendimento da natureza como sistemas autorregulados, integrados e em equilíbrio tiveram a mais forte ressonância no pensamento ambientalista nas últimas décadas. Para Hannigan (1995), ao simplificar e popularizar as leis gerais do ecossistema, autores como Rachel Carson e Garret Hardin conseguiram um grande poder retórico.

Porém, a ciência ecológica entendida como heterogênea e pluralística (MCINSTOSHI, 1987; DIAMOND; CASE, 1986; GOLLEY, 1993) não pode ser

\footnotetext{
${ }^{1}$ Alfred George Tansley (1871-1955) foi o primeiro a utilizar o termo ecossistema, em 1935. Esse autor entendia o ecossistema como um elemento na hierarquia dos sistemas físicos e, deste modo, como o sistema básico da análise ecológica (GOLLEY, 1993).
}

Caderno eletrônico de Ciências Sociais, Vitória, v. 1, n. 1, p. 1-17. 
reduzida à abordagem ecossistêmica, e mais especificamente a uma leitura específica desta última (ecossistema como superorganismo e autorregulado), que embora tenha sido detentora de certa hegemonia dentro da ecologia convive com uma pluralidade de abordagens, teorias e conceitos.

O principal pressuposto do paradigma clássico na ecologia é a ideia que os ecossistemas são unidades autorreguladas ${ }^{2}$ e que seguem uma trajetória linear de desenvolvimento em direção a uma particular diversidade biológica e um estado de estabilidade denominado clímax (FIEDLER et al., 1997). Em tal perspectiva os distúrbios (fogo, insetos, doenças e mesmo ação humana) são considerados muito mais como eventos externos do que propriedades intrínsecas dos sistemas ecológicos.

A partir da década de 1970 surgiram alguns trabalhos que questionaram a estrutura teórica em que a ecologia estava estabelecida até então. Fala-se mesmo no surgimento de uma nova ecologia (WORSTER, 1984; MCINTOSHI, 1985; BRAMWELL, 1989; BOTKIN, 1990; PICKETT et al., 1994; ZIMMERER, 1994) e de mudança de paradigma ${ }^{3}$ na ecologia (PICKETT et al., 1994; SCOONES, 1999).

Segundo Golley (1993), o conceito de ecossistema se ajusta bem à ideia de Thomas Khun de um paradigma, pois se trata de uma ideia dominante e organizadora no desenvolvimento da ecologia, principalmente nos EUA entre 1950-1965. A ideia de um sistema no qual interagem organismos e fatores ambientais, organizado em níveis tróficos, ligado através de fluxo de energia, dominou a ciência durante esse período. Segundo o autor, o trabalho de Odum de 1953, Fundamentos de ecologia, foi de fundamental importância para a dominância do conceito de ecossistema na ecologia. ${ }^{4}$

Para Pickett et al. (1994), os paradigmas disciplinares presentes dentro da ecologia estão assumindo atualmente novas configurações. 0 autor apresenta três principais paradigmas ecológicos que aparecem como contraste entre: 1 ) perspectivas baseadas no equilíbrio ${ }^{5}$ e no não equilíbrio;

\footnotetext{
${ }^{2}$ A noção de equilíbrio relacionada ao conceito de ecossistema aparece com Tansley, que tomou o equilíbrio como elemento central do seu conceito de ecossistema (GOLLEY, 1993).

${ }^{3}$ Num sentido amplo: um conjunto de premissas e conceitos básicos sobre os quais é construído um corpo teórico (KUHN, 1970).

${ }^{4}$ Segundo Golley (1993), o texto de Eugene Odum se diferenciava principalmente por ser curto, simples e enfatizar princípios e conceitos que Odum considerava elementos fundamentais da ciência dentro de uma estrutura lógica e coerente.

${ }^{5}$ Para Pickett (1994, p. 117), "The balance of nature is not a scientific theory or concept, but is a metaphor and cultural palimpsest with deep roots. It has supported the persistence of de classical paradigm in ecology".
} 
2) visões de controle unilateral e controles recíprocos; e 3) visões de causas simples e de múltiplas causas.

Para Scoones (1999), a metáfora do equilíbrio ganhou força na ecologia com o desenvolvimento de modelos tanto da ecologia vegetal como animal. No início do século $X X$, ecólogos da vegetação se interessavam por processos de sucessão explorando como uma associação de plantas mudava em direção a um clímax. A partir de 1930 a ecologia de populações se fortaleceu com o desenvolvimento de modelos de regulação das populações animais que descreviam um suposto equilíbrio entre taxa intrínseca de crescimento populacional e capacidade suporte. Vinte anos mais tarde, o conceito de sistema influenciou as ideias sobre o ecossistema na ecologia, identificado como complexo, integrado por níveis tróficos e por ciclos de energia e matéria e ao mesmo tempo regulado e equilibrado.

Segundo Wallington et al. (2005), a ideia de um equilíbrio inerente da natureza tem fornecido um forte argumento para a conservação da biodiversidade. Quando os ecossistemas são determinísticos, a conservação da natureza é relativamente uma tarefa simples: deixar os sistemas ecológicos livres de distúrbios, pois assim permanecerão em equilíbrio, conservando suas propriedades (composição de espécie e função) indefinidamente. Para os autores, esses pressupostos têm fornecido um conjunto de políticas de conservação, incluindo áreas protegidas, planejamento e gerenciamento de parques.

Como se vê, o paradigma do equilíbrio é uma das ideias mais antigas e dominantes na ecologia e foi fundamental no desenvolvimento do conceito de ecossistema (PICKETT et al., 1992). Porém, a partir dos anos 1970, assistiu-se à emergência de conceitos-chaves trazidos por teorias do não equilíbrio que foram baseadas sobre propriedades de sistemas não lineares, especialmente aqueles dominados por alto nível de variabilidade temporal e espaciais. Tal desenvolvimento recusa a ideia de um ponto estável de equilíbrio e de um estado de clímax dos sistemas ecológicos.

Dentro dessas teorias do não equilíbrio, Scoones (1999) cita três conceitos que forneceram importantes hipóteses e questões: o conceito de múltiplos estados estáveis - sistemas não lineares com mais de um equilíbrio -, o reconhecimento de uma dinâmica caótica em que as interações não lineares são sensíveis às condições iniciais (carência de previsibilidade em longo prazo) e, por último, o conceito de sistemas estocásticos não equilibrados sem mecanismos regulatórios simples.

Especificamente na ecologia vegetal, os recentes estudos de sucessão buscam compreender causas próximas de mudanças na vegetação e assumem um paradigma de não equilíbrio frente a condições ambientais. $\mathrm{Na}$ 
visão contemporânea da dinâmica de vegetação, não há a pressuposição absoluta de estabilidade ambiental do sítio nem a definição a priori de um estágio final da sucessão; ao contrário, dá-se ênfase à observação de distúrbios frequentes, repetidos e da variação contínua da vegetação, em várias escalas de tempo e de espaço (GLENN-LEWIN et al., 1992).

Os distúrbios são reconhecidos como características intrínsecas à dinâmica dos sistemas ecológicos. Tais distúrbios podem ser naturais (queda de árvore, morte de indivíduos, mudanças climáticas) ou mesmo provocados pela ação humana. Desse modo, para Wallington et al. (2005), as condições atuais dos sistemas ecológicos devem ser entendidas no contexto de uma trajetória de mudanças que inclui formas de uso do solo passadas, clima, distúrbios naturais, além dos processos de sucessão endógenos. Os autores falam, portanto, de uma contingência histórica que reflete os padrões acumulativos de impacto de uma diversidade de processos em várias escalas.

Para Hobbs e Morton (1999), tais processos atuam no contexto de outros, o que pode tornar a ideia de uma sequência temporal de desenvolvimento dos sistemas ecológicos muito fragilizada, pois não é mais possível prever o ponto final de muitos processos de sucessão, já que vários estados são possíveis dependendo das circunstâncias contingentes.

O impacto dessas ideias na teoria ecológica, segundo Wallington et al. (2005), ocorre desde de o ponto de vista de que o paradigma do equilíbrio da natureza é simplesmente errado para a visão que admite a permanência dos conceitos centrais ancorada nas antigas ideias. Nesse aspecto, o novo paradigma apenas modificaria mais do que descartaria muitas dessas antigas ideias. Porém, segundo os autores, muito pouco dessa mudança de paradigma refletiu-se nos livros e textos de ecologia, bem como nas práticas de manejo dos recursos até recentemente, embora um grande número de mensagens-chaves para a conservação da biodiversidade tenha surgido desse novo modo de pensar a dinâmica espacial e temporal dos sistemas ecológicos (DRURY, 1998).

Adams (1997), por exemplo, descreve o desenvolvimento de instituições de conservação e ideologias no Reino Unido, considerando o modo como a ecologia (particularmente as ideias de equilíbrio) forneceu uma estrutura intelectual para a conservação. Para o autor, a ecologia deu sustentação para o estabelecimento de instituições governamentais de conservação fornecendo estratégias intelectuais para classificar, objetivar e gerenciar a natureza. O autor ainda discute as implicações da abordagem da ecologia do não equilíbrio para as ideias e práticas de conservação. 
Em relação aos movimentos ambientalistas, que emergiram em várias partes do planeta a partir de 1970, para Scoones (1999), de certa forma, todos adotaram a metáfora do equilíbrio da natureza em seus repertórios discursivos. Nas várias tendências do ambientalismo (tecnocrático, ecocêntrico, gerencialista, ético-espiritual), o tema do equilíbrio da natureza é uma noção comum. Do mesmo modo, para Weiner (1996, p. 6), "[...] the old ecology is the ideology most closely associated with the tidal wave of environmentalism and environmental legislation... since 1969. It rests on two foundational propositions: nature is in balance, and human action disturbs that balance".

\section{A concepção do ecossistema em equilíbrio: a contribuição da ideia de superorganismo de Frederic Clements}

Na ecologia vegetal, os trabalhos de Frederic E. Clements (1874-1945) contribuíram para o estabelecimento das principais ideias que compõem a base da ecologia clássica ou do "antigo paradigma" (WORSTER, 1984; MCINTOSHI, 1985; PICKETT, 1994). As ideias de comunidade ecológica como um organismo e de um estágio clímax no desenvolvimento dessas comunidades estruturaram o pensamento ecológico durante grande parte do século XX. A própria elaboração teórica do ecossistema como unidade fundamental da natureza e, consequentemente, da análise ecológica tem na abordagem de Clements forte elemento de sustentação.

Embora seja mais comum pensar nas ciências naturais, especificamente na biologia, como influência mais direta entre teóricos sociais nos primórdios da sociologia - tanto na interpretação naturalista dos fenômenos sociais como na aspiração de leis de funcionamento da sociedade (CUIN; GRESLE, 1994) -, uma breve observação dos contextos intelectual e ideológico envolvidos no desenvolvimento teórico de Clements indicará que a sua compreensão dos fenômenos ecológicos foi influenciada por um conjunto de ideias sociais (e filosóficas) que tiveram importante papel na constituição de um arcabouço teórico da ecologia.

Mais especificamente, Tobey (1981 apud GROSS, 2002) acredita que o conceito de comunidade de Clements foi diretamente derivado das ideias de comunidade em sociologia, emprestando desta última a noção que descrevia uma unidade social como um tipo de organismo. Num ambiente influenciado pelas ideias organicistas de Herbert Spencer (1820-1903), 
Tobey reconhece os trabalhos do sociólogo Lester F. Ward (1841-1913) ${ }^{6}$ como uma influência prévia sobre o pensamento de Clements. McIntoshi (1985) também coloca as visões de Clements e de Artur G. Tansley (18711955) da ecologia como próximas das ideias sociais do período.

Clements foi um dos principais autores que fez a ecologia se estabelecer como ciência e sua contribuição se estendeu desde novas teorias a novos métodos e instrumentos de pesquisa (WORSTER, 1984). Clements contribuiu para o desenvolvimento e consolidação dos conceitos de comunidade e sucessão vegetal na ecologia e foi um dos primeiros estudiosos a apresentar uma teoria abrangente e sistematizada da sucessão vegetal. Para Glenn-Lewin et al. (1992), tão respeitadas foram a ordem e a lógica da teoria de Clements que a mesma dominou o campo da ecologia vegetal na América do Norte até a metade do século $X X$, sendo que os aspectos mais controversos da teoria da sucessão de Clements giram em torno dos problemas da previsibilidade, convergência e equilíbrio.

Para Clements, a sucessão é um processo altamente ordenado ${ }^{7} \mathrm{e}$ previsível no qual mudanças na vegetação representam a história de vida da comunidade vegetal, que nasce, cresce, atinge a maturidade e morre (atributos de um organismo para a comunidade). A partir de diferentes pontos de partida determinados ambientalmente, as comunidades se substituiriam e convergiriam através do processo de sucessão em direção a uma vegetação clímax, unicamente controlada pelo clima regional, portadora de grande estabilidade e em equilíbrio ${ }^{8}$ com este (GLENN-LEWIN et al., 1992; PILLAR, 2002).

Muitas críticas foram dirigidas à teoria de sucessão de Clements no período de sua publicação. Henry A. Gleason (1882-1975) e Henry C. Cowles (1869-1939) questionaram a ideia da comunidade de plantas como uma unidade orgânica altamente integrada, como também a ideia de que toda mudança da vegetação em uma região particular convergiria para um mesmo tipo de clímax. Tais autores criticaram a direcionalidade do processo de Clements, afirmando que dadas todas as combinações possíveis da causa da sucessão seria impossível determinar a direção de um processo e em que ponto ele culminaria (ROLIM, 2006).

\footnotetext{
${ }^{6}$ Primeiro presidente da Sociedade Americana de Sociologia (1906-1907) e, segundo Gross (2002), o mais influente sociólogo americano do final do século XIX.

7 Tomando as formas de teorias designadas como evolucionistas em Hirst (1977), pode-se pensar na teoria de sucessão de Clements como teleológica ao passo que estabelece um processo com uma direção definida e um fim obrigatório.

${ }^{8}$ Nesse sentido, equilíbrio pode ser entendido como um estado estável no qual ocorre uma mínima variação nos parâmetros fundamentais da comunidade.
} 
Como contraponto à ideia de unidade orgânica da comunidade de plantas, Gleason (1926) ressalta o papel do indivíduo, o comportamento individualista das espécies de plantas e o papel de eventos aleatórios, contrapondo assim o conceito de associação como unidade discreta. A comunidade é vista como resultado fortuito da sobreposição da distribuição de espécies com tolerâncias ambientais semelhantes.

Quanto à sucessão, Gleason entendia como um processo mais dependente dos indivíduos e de fatores de oportunidade, com resultados imprevisíveis (ROLIM, 2006). Gleason enfatizava assim a importância de processos estocástiscos na sucessão. Wallington et al. (2005) veem em Gleason o precursor do paradigma do não equilíbrio na ecologia.

Como já colocado, as ideias de Clements a respeito de comunidade de plantas e sucessão foram de certa forma hegemônicas na ecologia até a metade do século XX, apesar das várias críticas recebidas. Mesmo a partir de 1960, Ramon Margalef (1919-2004) e Eugene Odum (1913-2002) procuraram conjuntamente desenvolver uma nova teoria unificada a respeito da sucessão, porém assumindo os mesmos princípios filosóficos de Clements.

Margalef aplicou a teoria da informação para os sistemas ecológicos como estratégia de buscar e explicar padrões universais para o processo de sucessão. A sucessão passa a ser entendida como incremento de informação num ecossistema, partindo de ecossistemas mais simples para mais complexos, com maior número de níveis tróficos e maior diversidade de espécies (PILLAR, 2002). Para Glenn-Lewin et al. (1992), embora frágil a ligação entre canais de informações e complexidade estrutural, as ideias de Margalef foram atrativas para ecólogos que procuravam uma explicação universal pós-climentsiana para a sucessão.

Dentro dessa mesma perspectiva, para Odum, o processo da sucessão convergiria para um sistema com máxima biomassa e biodiversidade, e portador de grande homeostase. As ideias de Clements, Margalef e Odum a respeito do processo de sucessão se aproximam das ideias evolucionistas de Spencer, principalmente do conceito de progresso deste último, como transformação do simples para o complexo, da homogeneidade para a heterogeneidade mediante a transformação da estrutura e da substância (HIRST, 1977).

Embora essas ideias tenham ganhado força e espaço na ecologia com muitos seguidores, em grande medida carecem de uma base empírica segundo Glenn-Lewin et al. (1992). De acordo com esses autores, poucos desses modelos foram cuidadosamente testados e na maioria dos casos os testes não têm proporcionado bases para tais hipóteses, sendo que tais 
modelos baseados na existência de forças determinísticas que convergem para uma grande homeostase, máxima informação ou para um superorganismo clímax representam mais uma filosofia de como a natureza deveria ser do que uma teoria derivada de dados empíricos.

Desde meados de 1970, Glenn-Lewin et al. (1992) afirmam que duas grandes mudanças conceituais têm dominado os pesquisadores sobre dinâmica de vegetação. Em primeiro lugar, uma substituição de explicações holísticas do fenômeno da sucessão por abordagens mecanicistas e reducionistas que enfatizam causas particulares da mudança da vegetação. Em segundo lugar, uma mudança do paradigma de equilíbrio para o de não equilíbrio. Para os autores, tais mudanças não implicam uma falta de preocupação com a previsão (ainda central nos estudos de dinâmica de vegetação), porém tais previsões são derivadas empiricamente a partir do conhecimento dos mecanismos de mudança de vegetação e aplicadas a uma localidade particular em vez de serem derivadas dedutivamente de teorias aplicáveis universalmente.

De acordo com paradigma do não equilíbrio o processo de sucessão é muito menos determinístico do que previamente se pensava. Os distúrbios são reconhecidos como uma característica inerente à dinâmica interna dos sistemas ecológicos e sua frequência tornam os sistemas ecológicos sujeitos a mudanças não previsíveis. Do mesmo modo, um ponto final do processo de sucessão nem sempre é aparente, e o equilíbrio assim torna-se um artefato temporário da observação e não uma propriedade intrínseca dos sistemas ecológicos (WALLINGTON et al., 2005).

Argumenta-se a seguir que a abordagem da ciência ecológica, baseada nas explicações holísticas e na ideia de um equilíbrio inerente aos ecossistemas, teve grande visibilidade, principalmente por ser esta a perspectiva adotada pelos movimentos ambientalistas a partir das décadas de 1960 e 1970.

\section{O papel dos conceitos e ideias ecológicas nos movimentos ambientalistas a partir de 1960}

A ciência ecológica teve um papel central na emergência do meio ambiente enquanto problema social (YEARLEY, 1989; HANNIGAN, 1995). Para Scoones (1999), embora em muitos casos o discurso ambientalista se apresente hostil à ciência moderna, ao mesmo tempo depende da autoridade social de um grupo particular da ciência ecológica (com sua aparente neutralidade e objetividade) para argumentar sobre a destruição 
da natureza, a ameaça da estabilidade dos ecossistemas ou o esgotamento da capacidade de suporte.

Nesse processo de construção social dos problemas ambientais envolvendo a ecologia, destacam-se tanto o envolvimento dos membros da ciência ecológica mais diretamente com a causa ambiental como a utilização, pelos grupos ambientalistas, de um conjunto de ideias dessa ciência.

Após a década de 1950, tanto a Sociedade Ecológica Americana quanto a Britânica foram relutantes no engajamento dos seus membros na defesa de posições particulares ou em prática de lobby. Era claro um conflito entre a imagem de uma ciência objetiva e desprovida de valor para uma ecologia conduzida por valores e guiada por uma ética humana, animal e mesmo vegetal. Porém, nos relatórios anuais das duas sociedades, observava-se que as preocupações com os problemas ambientais eram notórias e constantes; muitos ecólogos individuais gastavam parte do seu tempo com as preocupações ambientais (EGERTON, 1977; MCINTOSHI, 1985).

O Comitê de Ecologia Aplicada da Sociedade Ecológica da América lamentava a política de uso do solo nos EUA ao questionar a ausência de critérios ecológicos em tais políticas e reivindicava um papel da ecologia na política, o que causou certa instabilidade entre pesquisadores da ecologia básica e aplicada, principalmente em torno de recursos para a pesquisa. Havia, portanto, uma posição forte de engajamento nas questões relacionadas às preocupações ambientais (MCINSTOSHI, 1985).

Para McIntoshi (1985), nos anos 1970, em face da multiplicidade de problemas ambientais, a ecologia, tanto no seu sentido estrito como disciplina científica quanto como um normativo modo de vida, ganhou visibilidade. Falava-se entre ecólogos e não ecólogos numa era da ecologia. Membros da Sociedade Ecológica da América pressionaram para a formação de um instituto nacional de ecologia, como uma agência governamental com o objetivo de aumentar a aplicação da ciência ecológica nos problemas sociais e ambientais. Por outro lado, alguns autores como Nelkin (1976) e Dunnett (1982) discutem as implicações das preocupações ambientais para a ciência ecológica que, segundo eles, distorceram o significado desta última. Para Dunnett (1982, p. 2), que foi presidente da Sociedade Ecológica Britânica:

It is especially important to be distinguished from the so-called 'environmentalists' or 'conservationists' whose attitudes and activities are based on value judgments, even though in the biological field, they depend heavily upon the knowledge and understanding that is

Caderno eletrônico de Ciências Sociais, Vitória, v. 1, n. 1, p. 1-17. 
provided by ecological research. The distinction of course, is not made easier by the fact that many ecologists are also conservationists and may indeed sometimes be found in opposing camps. As scientists we are accustomed to this, but it may reduce our credibility in the eyes of others. So far, I have been commenting upon the imprecise and often incorrect use of ecological terms by a wide variety of people.

Mesmo antes da explosão das preocupações ambientais nos anos 1960, a ecologia tinha fortes vínculos com os grupos conservacionistas, ${ }^{9}$ seja por meio do envolvimento de seus membros com esses grupos ou pela simples mobilização da argumentação científica. A ecologia era considerada uma grande aliada científica para a argumentação pública conservacionista (EGERTON, 1977; MCINSTOSHI, 1985; YEARLEY, 1989; ADAMS, 1997) e, deste modo, os membros dos grupos conservacionistas tornavam-se portadores de um discurso cientificista que viam nos cientistas naturais, de forma geral, a máxima autoridade na definição dos problemas e das políticas ambientais (ALONSO et al., 2004).

Os movimentos ambientais que emergiram em torno do mundo, principalmente a partir da década de 1960, encontraram na ecologia ideias e conceitos para a construção de um conjunto de argumentos. Dessa forma, pode-se dizer que a ecologia forneceu um "repertório" (ALONSO; COSTA, 2002), um estoque de símbolos e valores que foram mobilizados pelos agentes na construção de suas percepções.

Da mesma forma, para Golley (1993), nos Estados Unidos, os ecólogos, impulsionados pelo conceito de ecossistema, foram o centro do movimento ambiental. O foco sobre as questões ambientais, aliado aos movimentos políticos de estudantes no final da década de 1960, criou um estímulo social que contribuiu para a fase que Golley denomina de rápido desenvolvimento do conceito. Para o autor, o Programa Biológico Internacional - IBP (1968-1974) foi somente uma das expressões dessas atividades políticas e sociais.

Nesse contexto, alguns escritores e intelectuais tiveram um papel fundamental na popularização de muitos conceitos ecológicos, como Rachel Carson, Barry Commoner, Paul Ehrlich e Garret Hardin (EGERTON, 1977; RUBIN, 1994; HANNIGAN, 1995). Segundo Kwa (1987), esses autores apresentavam diferentes soluções para a então chamada crise ambiental,

\footnotetext{
${ }^{9}$ É importante considerar que tal vínculo tem raízes muito mais antigas, como retratado por Thomas (1988) e Dalton (1994), que descrevem o desenvolvimento das ciências naturais no século XIX e a preocupação dos seus membros com os problemas ambientais ao associar o processo de industrialização à extinção de habitat e espécies.
} 
embora compartilhassem uma visão comum da natureza: viam o homem como parte da natureza e defendiam o respeito pelo equilíbrio e pela homeostase da mesma. Nesse aspecto, o conceito de ecossistema de Odum e a ideia de que o ser humano participa ativamente dos ciclos biogeoquímicos foi de fundamental importância (GOLLEY, 1993).

Segundo Hannigan (1995), Rachel Carson, em Primavera silenciosa (1962), ao popularizar o conceito de ecossistema e suas leis, permitiu a sua centralidade no surgimento do movimento ambientalista a partir da década de 1960. É importante salientar que, nesse período, a abordagem de ecossistema - "metáfora da natureza como máquina cibernética" (KWA, 1987 , p. 425) -, além de não ser a única dentro da ciência ecológica como instrumento de compreensão dos fenômenos ecológicos, começava a ter alguns de seus conceitos questionados por um conjunto de novos trabalhos.

Golley (1993) entende que o conceito de ecossistema forneceu uma certa ordem no âmbito da complexidade da ciência ecológica. Tal capacidade do discurso científico de atribuir ordem e sentido ao mundo e seus fenômenos, quando inserida num período histórico de rápidas transformações sociais, era fonte de grandes expectativas por formas de discursos que poderiam restabelecer o "equilíbrio" social e ambiental.

Para Kwa (1987), a identificação da ecologia (mais especificamente a ecologia de sistemas) como um tipo de ciência básica necessária para fornecer uma base de conhecimento para a solução dos problemas ambientais foi fundamental para os grandes investimentos do International Biological Program (IBP) em pesquisas na área de ecologia de sistemas nos Estados Unidos. Segundo o autor, a correspondência entre uma metáfora constitutiva da ecologia de sistema (ecossistema como uma máquina regulada) e a representação da natureza em importantes segmentos da sociedade americana no final dos anos 1960 forneceram a esses ecólogos uma oportunidade para legitimar e desenvolver tal abordagem e também para mobilizar fundos. Para o autor:

The representations of nature current in cybernetic ecology, in the environmental movement of around 1970 (with, as an early protagonist, Rachel Carson), and those voiced by the witnesses to the Congress in 1967, are all related, if not identical. Apparently, the representation of nature as a machine to be controlled was dominant in the period immediately before and after 1970. This shared representation of nature made possible a shared conception of how environmental problems were to be defined, and how their solution should be envisaged. This made cybernetic-systems ecology appears as the natural candidate to do the job. The only thing needed was a

Caderno eletrônico de Ciências Sociais, Vitória, v. 1, n. 1, p. 1-17. 
crash programme which would make the concepts of systems ecology operational. The IBP would, it was hoped, provide this (KWA, 1987, p. 433).

A perspectiva ecossistêmica não era a única presente nos movimentos ambientalistas no final dos anos 1960 e início de 1970. Kwa (1987) aponta a argumentação ancorada numa dimensão ética de que a natureza tem um valor em si, como uma importante base dos movimentos ambientais americanos, que de certa forma poderia se sustentar sem a perspectiva do ecossistema (ancorada pela ciência). Porém, segundo o autor, foi esta última que se tornou dominante nos movimentos ambientalistas.

Já para Hannigan (1995), foi justamente a fusão entre ecologia e ética um aspecto fundamental para o fortalecimento do movimento ambientalista. Para o autor, enquanto construção teórica, o ecossistema passa a ser entendido também com significado moral e as intervenções na comunidade biótica passam a ser encaradas como algo errado de se fazer. Da mesma forma para Scoones (1999), metáforas do equilíbrio ecológico (central na abordagem ecossistêmica) são utilizadas para estabelecer posições morais e éticas e mesmo para justificar intervenções no ambiente.

Desse modo, para Hannigan (1995), a ecologia foi transformada de um modelo científico para o entendimento das comunidades de plantas e animais para uma espécie de arma organizacional que poderia ser utilizada para sistematizar, expandir e moralmente revigorar a mensagem ambiental. Nesse processo, a ecologia adquiriu nova textura, mais política, mais universal e mais subversiva. Segundo o autor, enquanto muitos ecólogos reagiram negativamente a essa reconstrução do conceito, outros apoiaram justificando que a crise ambiental demandava um novo senso de ativismo social por parte dos pesquisadores biológicos.

Da mesma forma, para MacDonald (1991 apud HANNIGAN, 1995), ao cooptar a ecologia científica, o movimento ambiental adicionou consideravelmente força política. Em primeiro lugar, permitiu aos ambientalistas reivindicar a autoridade da ciência para suas campanhas; e em segundo lugar, por meio de uma abordagem holística, a ecologia atraiu uma variedade de seguidores que de outro modo teriam pouco interesse na causa verde.

\section{Considerações finais}

Como apresentado anteriormente, o conceito de ecossistema relacionado à ideia de equilíbrio desempenhou um papel constituidor e ao 
mesmo tempo estratégico nos discursos ambientalistas a partir da década de 1960.

Nesse período, a abordagem ecossistêmica baseada na totalidade e na autorregulação detinha grande hegemonia na ciência ecológica ou utilizando os termos de Bourdieu (1976), ao se referir ao campo científico os ecólogos dessa abordagem desfrutavam de posições hierarquicamente reconhecidas como dominantes ao dispor de maior capital científico (maior autoridade científica). Ao mesmo tempo, detinham o poder de impor para outros componentes do mesmo campo a definição de ciência que se conformava melhor a seus interesses específicos, ou seja, aquela que garantiria legitimidade à posição dominante. Nesse sentido, os grandes investimentos em programas como o IBP denotam o reconhecimento da legitimidade dessa leitura particular dos fenômenos ecológicos.

Porém, muitas das premissas de tal abordagem foram continuamente rebatidas por novos trabalhos que questionaram a possibilidade dos ecossistemas funcionarem de forma determinística e, consequentemente, enfraqueceram a ideia de equilíbrio como pensada anteriormente. Nesse sentido, o reconhecimento dos distúrbios (naturais ou humanos) como inerentes aos sistemas ecológicos possibilitou uma releitura das representações da natureza.

No entanto, conforme apontado por um conjunto de autores, tal releitura no âmbito da ciência ecológica em relação aos conceitos e noçõeschaves parece não ter sido refletida nas estratégias discursivas dos movimentos ambientalistas contemporâneos. Tais discursos, de um modo geral, ainda estão ancorados numa concepção de equilíbrio estático dos sistemas ecológicos.

Para finalizar, este artigo traz o seguinte questionamento: quais seriam as implicações políticas e cognitivas para os movimentos ambientalistas ao assumir condicionantes históricos (forças naturais e humanas) na estruturação das comunidades biológicas? O reconhecimento de que forças sociais não sejam necessariamente fatores de destruição e degradação dos sistemas ecológicos certamente exigirá uma redefinição da noção de impacto ambiental e do grau aceitável de intervenção e de exploração dos recursos naturais nas arenas institucionais e políticas. Tais processos tendem a se caracterizar como altamente contingentes e conflitivos. 


\section{Referências}

ADAMS, W. M. 1997. Rationalization and conservation: ecology and the management of nature in the United Kingdom. Transactions of the Institute of British Geographers, vol. 22 (3), p. 277-291.

ALONSO, $A$; V COSTA. 2002. Por uma sociologia dos conflitos ambientais no Brasil. In: Alimonda, Hector (org.). Ecologia Política. Natureza, sociedad y utopia. Buenos Aires: Clacso - Conferência Latino-americana e Caribenha de Ciências Sociais, 2002, v. p. 115-135.

ALONSO, A; COSTA, V.; MACIEL, D. 2005. The formation of the Brazilian environmental movement. IDS Working Paper, v. 259, p. 1-36.

BOTKIN, D. B. 1990. Discordant Harmonies: A New Ecology for the TwentyFirst Century. 1. ed. Oxford, UK: Oxford Univ. Press.

BOURDIEU,P. 1994. O campo científico. In: R. Ortiz (org.), Pierre Bourdieu, São Paulo, Ática.

BRAMWELL A. 1989. Ecology in the 20 ${ }^{\text {th }}$ Century: A History. 1 ed. Yale University Press.

CLEMENTS, F. E. 1928. Plant Succession and Indicators: A definitive edition of plant succession and plant indicators. 1 ed. New York. Hafner Press.

DIAMOND, J; CASE, T. J. 1986. Community Ecology. 1.ed. New York. Harper \& Row.

DRURY, W.H. 1998. Chance and Change: Ecology for Conservationists. 1 ed. University of California Press.

DUNNETT, G. M. 1982. Ecology and Everyman: Presidential Address to the British Ecological Society. The Journal of Animal Ecology, vol. 51, n. 1. p. 1-14. (Feb.).

EGERTON, F. 1977. History of American Ecology. 1 ed. New York. Arno Press (History of ecology collection).

FIEDLER, P.L., WHITE, P.S., LEIDY, R. A. 1997. The paradigm shift in ecology and its implications for conservation. In: Pickett S. T. A., Ostfeld, R. S. Shachak M. Likens, G. E. The ecological basis of conservation: heterogeneity, ecosystems, and biodiversity. New York, Chapman and Hall, p. 83-92.

GLENN-LeWIN, D. C; PEET, R.K; VEBLEN, T.T. 1992. Plant Succession: Theory and prediction. 1 ed. Cambridge. University Press.

GOLLEY, F. B. 1993. A history of the ecosystem concept in ecology. New Haven, CT: Yale University Press.

GROSS, M. 2002. When ecology and sociology meet: The contributions of Edward A. Ross. Journal of the History of the Behavioral Sciences. Vol. 38 , Issue 1 , p. 27-42. 
HANNIGAN, J. A. 1995. Environmental Sociology: a social constructionist perspective. 1 ed. Environment and Society.

HIRST, P. Q. 1977. Evolução Social e Categorias Sociológicas. 1 ed. Rio de Janeiro. Zahar Editores.

HOBBS, R. J; MORTON, S. R. 1999. Moving from descriptive to prescriptive ecology Agroforestry System, v. 45, p. 43-55.

KUHN, T. S. 1970. The structure of scientific revolutions. 2 ed. University of Chicago Press, Chicago.

KWA, C. 1987. Representations of Nature Mediating between Ecology and Science Policy: The Case of the International Biological Programme. Social Studies of Science, vol. 17, n. 3. p. 413-442. (Aug.).

MCINTOSHI, R. P. 1987. Pluralism in ecology. Annual Review of Ecology and Systematics. Vol. 18. p. 321-341.

MCINTOSHI, R. P. 1985. The background of ecology: concept and Theory. Cambridge, UK. Cambridge Univ. Press.

MOORE, N. M. 1987. The Science and Politics of Nature Conservation. 1 ed. Cambridge University Press.

NELKIN, D. 1976. Ecologists and the Public Interest. The Hastings Center Report, Vol. 6, No. 1. p. 38-44. (Feb.).

NICHOLSON, M. 1989. The New Environmental Age. 1 ed. Cambridge University Press.

PICKETT, S. T. KOLASA, A. J. JONES. C. G. 1994. Ecological understanding: the nature of theory and the theory of nature. 1 ed. New York. Academic Press.

ROLIM, S. G. 2006. Modelos e mecanismos de sucessão secundária na floresta atlântica em Linhares (ES). Tese (Doutorado em Recursos Florestais). Universidade de São Paulo. Escola Superior de Agricultura Luis de Queiroz. Piraciacaba.

RUBIN, C. T. 1994. The Green Crusade: Rethinking the Roots of Environmentalism. 1 ed. Rowman \& Littlefield Publishers.

SCOONES, I. 1999. New Ecology and the Social Sciences: What Prospects for a Fruitful Engagement? Annual Review of Anthropology, Vol. 28, p. 479-507.

THOMAS, K. 1988. O Homem e o Mundo Natural. São Paulo. Companhia das Letras.

TOWNSEND, C. R; BEGON, M; HARPER, J. L. 2006. Fundamentos em Ecologia. 2 edição. Porto Alegre RS. Artmed.

WALLINGTON, T. J; HOBBS, R. J; MOORE, S. A. 2005. Implications of current ecological thinking for biodiversity conservation: a review of the salient issues. Ecology and Society 10(1): 15. 
WEINER, D. 2000. Models of Nature: Ecology, Conservation, and Cultural Revolution in Soviet Russia. Pittsburgh: University Of Pittsburgh Press.

WIENER, J. B. Beyond the Balance of Nature. 1996. Duke Environmental Law \& Policy Forum 7(1), p. 1-24.

WORSTER, D. 1984. Nature's Economy: A History of Ecological Ideas. 2 Ed Cambridge, UK: Cambridge Univ. Press.

YEARLEY, S. 1989. Review: Environmentalism: Science and a Social Movement. Social Studies of Science, vol. 19, n. 2. p. 343-355. (May).

ZIMMERER, K. S. 1994. Human Geography and the "New Ecology": The Prospect and Promise of Integration. In: Annals of the Association of American Geographers. V. 84 (1), p. 108-125. 